\title{
EDITORIAL
}

\section{Give, Live, Inspire}

For referencing Montgomery E. Give, Live, Inspire. Transplant Journal of Australasia 2021; 30(3):4.

DOI https://doi.org/10.33235/tja.30.3.4

The theme of our December edition aligns with that of the 2021 TNA National Conference - Give, Live, Inspire. Give, Live, Inspire encapsulates the true nature of transplant nursing and is reflected in the articles featured in this edition. Transplant nurses possess a unique skillset, unwavering commitment and passion which are at the core of their day-to-day work. Work that not only saves lives but touches the lives of transplant recipients, their families and extends throughout their communities. This year has continued to challenge transplant nurses and how they provide care to their patients. Despite this, transplant nurses remain steadfast advocates for their patients and have evolved their delivery of care to continually meet the needs of patients and their families.

As we move into the New Year, we will continue to face some of the challenges we have dealt with over recent times. Whether it be ongoing challenges associated with the pandemic, navigating your way as a first-time author, or simply finding the drive to head into your next shift, transplant nurses possess the qualities to face 2022 head on.

In this edition, we are proud to feature the abstracts presented at the 2021 TNA National Conference and the conference report from South Australian State President Jane van der Jeugd. The South Australian TNA Conference Committee delivered an engaging and thought-provoking conference via the virtual platform. Well done to the joint winners of the best conference paper award - Denise Lawrence for Access to renal transplantation for the incarcerated patients, a matter of health equity and Belinda Bourne for Locked down but not out: continuing the National Paediatric Lung Transplant Program during the COVID-19 pandemic.

Professor Kay Wilhelm, consultant psychiatrist, consultation liaison psychiatry at St Vincent's Hospital, Sydney, presents our guest editorial. Professor Wilhelm provides insight into the world after lockdown and advice for transplant nurses caring for patients who may be finding it difficult to navigate their way out of lockdown. This advice is of particular interest to those living in states that have recently come out of lockdown but is also relevant to the wider transplant community as borders start to reopen and we slowly move towards a world resembling the one we knew before the pandemic.
The demands across the organ donation and transplantation sector are continually evolving. The Organ and Tissue Authority (OTA) have kindly provided two articles - The expansion of OrganMatch to meet the needs of the Australian donation and transplantation sector and Transitioning to a national virtual crossmatch protocol for solid organ transplant offers in Australia. The articles describe how their processes are advancing to meet the increasing complexities of the industry and to streamline practice.

We feature two first-time authors in our December edition. It takes courage and a lot of hard work as a first-time author. Cathy Martin, a social worker from Princess Alexandra Hospital, Brisbane, presents her article discussing the solution-focused approach and its relation to transplant patients. Cathy presented her work at the 2021 TNA National Conference and has developed it into an article. In her case study, Lucinda Lyle, clinical nurse educator, renal services, Westmead Hospital, Sydney, explores the nursing care and considerations in a patient with post-transplant lymphoproliferative disease following renal transplant. I recognise and appreciate the commitment and diligence of both Cathy and Lucinda during the write-up of their articles. I am sure they will inspire other first-time authors to share their valuable experience and knowledge through the TJA.

I would like to acknowledge and thank the TNA National Executive. Your continued hard work and unwavering dedication allow the TNA and the TJA to thrive. To the TJA Editorial Board, particularly Libby John, a huge thank you for your ongoing commitment and support. We often work with tight timelines, and I appreciate the many hours you dedicate to ensuring the TJA supports our authors and publishes quality work to disseminate amongst our colleagues.

Finally, I wish you all a safe and happy holiday period and look forward to a successful and productive year ahead. 